\title{
How Much Irrationality Does the Market Permit?
}

\author{
Alan Schwartz
}

\begin{abstract}
This article asks whether competition can ameliorate the consequences of cognitive error. Consumers differ cognitively, some being more prone to err (the "naive") than others (the "sophisticated"). Competition among firms is analyzed with a search equilibrium model. Firms offer an exploitative contract or a naive contract to a consumer population partitioned in two ways: some consumers are sophisticated while others are naive, and some consumers search for preferred contracts while others visit one firm. There are two principal results. First, when consumers shop, neither contract type is priced monopolistically, and competitive pricing sometimes obtains. Second, when enough consumers are sophisticated and the naive have a relatively low willingness to pay for their preferred contract, exploitative contracts decline in frequency and may actually vanish. These results suggest that while decision makers should continue to ask if consumers suffer from cognitive error, they also should ask whether markets do, or could be helped to, ameliorate error's consequences.
\end{abstract}

\section{INTRODUCTION}

\subsection{Consumer Heterogeneity regarding Cognitive Error}

This article asks whether market competition can ameliorate the effect of cognitive error. Much of the policy literature asks the converse ques-

alan SChwartz is Sterling Professor of Law and Professor of Management at Yale University. An early version of this article was given as the Addison Harris Lecture at the Indiana University Law School, Bloomington. The current version was improved by presentations at the meeting of the American Law and Economics Association, the Virginia Law School, the New York University Law and Finance Workshop, and the Yale Law School. Ian Ayres, Oren Bar-Gill, Ezra Friedman, Alvin Klevorick, Daniel Markovits, Gregory Mitchell, Stephen Morse, Eric Posner, Rip Verkerke, and an anonymous referee made helpful comments.

[Journal of Legal Studies, vol. 37 (January 2008)]

(C) 2008 by The University of Chicago. All rights reserved. 0047-2530/2008/3701-0004\$10.00 
tion, how the presence of cognitive error affects market performance. This literature makes a homogeneity assumption. Persons (all of them) are assumed to make particular cognitive mistakes, or no one does. Consequently, in contexts where mistakes are thought to be made, regulation in some form seems warranted.

This belief may be overstated because the homogeneity assumption is inaccurate. Psychologists believe that an experimental subject succeeds when she makes the choice that maximizes her overall well-being. This choice is denoted the "normative response." A nontrivial fraction of subjects in psychological experiments give the normative response.

This heterogeneity result arises because persons process information with one or the other of two distinct systems. "System 1 is viewed as encompassing primarily the processes of interactional intelligence. It is automatic, largely unconscious, and relatively undemanding of computational capacity. . . . [I]t conjoins properties of automaticity and heuristic processing. . . . System 2 conjoins the various characteristics that have been viewed as typifying controlled processing. System 2 encompasses the processes of analytic intelligence that have traditionally been studied in psychometric work and that have been examined by information-processing theorists trying to uncover the computational components underlying psychometric intelligence" (Stanovich 1999, p. 204). ${ }^{1}$

Cognitive theory experiments are designed such that one informationprocessing system will yield a particular response but the other will yield a different response. The experimenter's goal is to see which system governs how subjects perform the experimental task. For example, the scenarios used in framing problems intuitively seem different to subjects-the system 1 result-but analysis would show that the scenarios actually describe the same problem-the system 2 result. Subjects whose behavior is controlled by system 2 are not misled by how the question is posed. Subjects whose behavior is controlled by system 1 make errors.

1. See also Strack, Werth, and Deutch (2004, p. 222): "Social behavior is the effect of two distinct systems of information processing: a reflective system and an impulsive system. ... In the reflective system, . . . knowledge about the value and probability of potential consequences is weighed and integrated to reach a preference for one behavioral option. . . . In contrast, the impulsive system activates behavioral schemata through spreading activation, which may originate from perceptual input or from reflective processes." See also Kahneman (2003, pp. 1451-52): "[T]he intuitive operations of System 1 generate impressions of the attributes of . . . thought. . . . In contrast, judgments are always explicit and intentional, whether or not they are overtly expressed. Thus, System 2 is involved in all judgments, whether they originate in impressions or in deliberate reasoning." 
The data also show that performance on one laboratory task correlates positively with performance on others: subjects who make mistakes in one context tend to make them in other contexts. ${ }^{2}$

The correlation in performance across experiments is plausible. Subjects who give the normative response in an experiment score higher in intelligence, as measured by SAT scores, than do subjects who fail to give the normative response, and the former subjects also test higher on such personal traits as a tendency to intellectualize problems (Rydval and Ortmann 2004; Stanovich and West 2000). Since intelligence and personality are relatively invariant to context, smart, intellectual people make fewer mistakes in general than other persons. ${ }^{3}$ Also, persons do not come to the experimenter wearing signs that identify themselves as analytic or intuitive. Rather, when a psychology investigator is interested in who is who, she tests subjects ex post.

The psychology results suggest that markets possess two features relevant to the question asked here. First, market participants also should be heterogenous: there will be "system 2 persons," who are difficult to fool, and "system 1 persons," who are more easily misled. ${ }^{4}$ Second, in mass transactions, as in the experiments, it will often be difficult for

2. Stanovich's extensive review summarizes the studies $(1999$, p. 66$)$ : "[T] $]$ he direction of all of the correlations displayed in Tables 2.1 and 2.2 is consistent with the standard normative models used by psychologists when interpreting tasks in the reasoning and decision-making literature. Individuals giving the normative response in one task tended to give it on another-even when the task requirements were quite different. Also, in every single case, cognitive ability was positively associated with giving the normative responseindividuals of higher intelligence were relatively more likely to give the normative response. This was equally true for tasks where the normative response is the subject of great controversy as it was for the relatively uncontroversial tasks." A recent recognition in the literature that heterogeneity is the more defensible assumption is by Rachlinski (2006). In the same vein, "many households find adequate solutions to the complex investment problems they face, [but] some households make serious investment mistakes" (Campbell 2006, p. 1590).

3. Chiappe and MacDonald (2005, p. 20), summarizing studies, state, "There is evidence that people with higher $\mathrm{g}$ [the score for general intelligence] are better able to reason logically on a wide variety of tasks, including those in which people are prone to the systematic biases resulting from the radical contextualization characteristic of human thinking."

4. There are a few real-world examples. Agarwal et al. (2008) found that 60 percent of the consumers in their sample chose the credit card contract that minimized their total interest costs, while 40 percent did not. The probability of making the wrong choice declined with the dollar magnitude of the potential error. Agnew (2006, p. 940) found that "higher salaried employees tend to make significantly better [401(k)] choices," while other employees follow naive investment strategies. Yang, Markoczy, and Qi (2007) found that some consumers in credit card markets are excessively optimistic about their ability to make timely repayments, while others are not. 
sellers and lenders to identify who is who before the firm offers contracts to consumers.

Firms thus face a complex problem. A firm would like to present a deal in such a fashion as to cue the system 1 response if consumers exhibiting that response would accept less favorable terms than would more analytical consumers. For example, persons are said to be overly optimistic about their future earnings prospects. Such persons may formulate financial plans that entail the willingness to accept lending contracts with low interest rates but harsh terms-for example, a term requiring the consumer to mortgage important assets-because they underestimate the probability of default. A firm that offers such contracts to everyone, however, could lose the business of system 2 persons (their financial plans would cause them to reject agreements with such harsh terms). Since firms compete for the marginal consumer, and sometimes will not know her type, competition among firms for the sophisticated, if there are enough of such persons, could cause firms to ignore the preferences of the naive.

It will be helpful, in pursuing this possibility, to divide unsophisticated consumers into two categories: those who know their flaws and those who do not. To see the point of this distinction, suppose that many consumers discount the future hyperbolically rather than exponentially. A hyperbolic discounter has a higher discount rate between tomorrow and today than she has between 6 and 5 months from today. ${ }^{5}$ Now consider a person who in January resolves that for the next year she will not spend more than $\$ 200$ each month above the amount required to satisfy her basic needs. In March, however, an MP3 player looks great to her. The consumer thus is at risk of being time inconsistent. In January, she would like to restrict her discretionary spending in the coming March, but when March arrives she may overconsume. Consumers who are aware of such present-based preferences may prefer to precommit not to spend excessively. Therefore, the market is more likely to offer

5. Considerable evidence exists that persons become more impatient as their payoffs move closer in time. The phrase "hyperbolic discounting" has become a shorthand for this type of behavior. Whether persons actually discount hyperbolically-whether their discount rates vary inversely with the time when payoffs are to be received-is becoming controversial. A good review is Frederick, Lowenstein, and O'Donaghue (2002). Shui and Ausubel (2005) find some evidence of hyperbolic discounting in credit card markets. For recent theoretical explanations of excessively present-based behavior, see Dasgupta and Maskin (2005) and al-Nowaihi and Dhami (2006). 
"naive contracts" to consumers who are unaware of their penchant to err.

\subsection{Identifying Naive Contracts}

An analyst testing this supposition must know what a naive or an irrational contract is, but no widely acceptable definition exists. To understand the definition used below, realize that a consumer may make two distinct mistakes: she can misconceive her type or misconceive the contract that would suit her type. A consumer misconceives her type when she is more optimistic, more confident, more present oriented, more swayed by anecdotal evidence than she should be. A consumer misconceives the contract when she correctly apprehends her type but prefers a contract that is inappropriate for that type. Cognitive error more frequently presents as a type mistake, and limited cognitive capacity more frequently presents as a contract mistake. This article is concerned with cognitive error, so the analysis below focuses on type mistakes. In this world, when the consumer buys a contract that appropriately matches her type, the contract is "sophisticated." A naive contract reflects a mismatch.

To make this definition a little more precise, suppose that contracts differ in quality, where quality is a function of the consequences that attach to breach either by the firm or by the consumer. As examples, a contract with a broad warranty is of higher quality than a contract with a narrow warranty because the broad warranty affords the consumer more relief when the seller breaches. A lending agreement with a narrow security interest (or none) is of higher quality than an agreement with a broad security interest because default is less costly to the consumer when she can keep more of her property. Now let a consumer's circumstances be such that she would purchase a warranty of quality $q^{\text {h }}$ if she knew the true odds of defects, unless $q^{\text {h }}$ carried a very high price. The consumer's search reveals the $q^{\mathrm{h}}$ warranty and a lower quality warranty, $q^{1}$, both of which are priced competitively. The sophisticated version of this consumer, who knows the odds, would pay the price premium for the high-quality warranty $q^{\mathrm{h}}$, while the naive version of this consumer (she is optimistic regarding the defect probability) would purchase the lower quality but lower priced warranty $q^{1}$. The lower quality warranty reflects a mismatch between the consumer's type and her contract choice. $^{6}$

6. A broader definition would define a mismatch as the choice of a nonmaximizing 
The analysis below supposes for convenience that consumers are in similar circumstances and come in two types: sophisticated and naive. Contracts come in two qualities: high (for example, the broad warranty) and low. Firms specialize in selling either high- or low-quality contracts. Whenever a consumer purchases a contract that is more favorable than her type would justify, the situation would qualify as a mismatch, but more severe consequences can visit consumers who mismatch on the low side. Accordingly, low-quality contracts (that is, narrow warranties) are denoted naive in the analysis below because they are more likely than high-quality contracts to reflect disadvantageous mismatches resulting from cognitive mistakes. High-quality contracts are denoted sophisticated because they are less likely to reflect such unfortunate mismatches. A naive consumer may nevertheless buy the $q^{\mathrm{h}}$ warranty if it is priced much below the low-quality warranty; similarly, a sophisticated consumer may rationally purchase the $q^{\mathrm{l}}$ warranty if $q^{\mathrm{h}}$ is monopolistically priced. Thus, equilibria may exist in which both contract types trade. ${ }^{7}$

Banning contracts that are described here as naive seems unwise. The assumption that all consumers are in similar circumstances is strong. When it is relaxed, some consumers (perhaps they are cash constrained) may rationally prefer to gamble with a narrow warranty. Another regulatory strategy would be to identify the naive and regulate what they buy, but this has obvious difficulties. A third strategy would be to correct the possibly applicable biases themselves. Section 4.3 will argue that this strategy is wise for schools but not for other institutions.

\subsection{This Article}

This article pursues a fourth strategy: it takes consumers as they are and asks whether markets can help the naive. Market competition could cause firms to respond to cognitive error in three nice ways: $(a)$ to offer contracts that sophisticated consumers prefer to all consumers, $(b)$ to offer contracts to self-aware error-prone persons to permit these consumers to avoid serious trouble, or $(c)$ to offer naive contracts but to

contract. For example, a consumer who expected to borrow a lot would be better off with a credit card contract that had an introductory fee and a low annual rate, while a consumer who expected to borrow a little would do better with a contract that had no introductory fee and a high annual rate. A consumer who incorrectly believes she will borrow little, in consequence of optimism about her prospects, is mismatched if she chooses the contract with an introductory fee. The text focuses on utility-minimizing contracts in the breach context because they have attracted much of the policy attention.

7. The prices at which consumers will purchase their less preferred contracts are precisely defined in the model below. 
price them competitively, so that inefficiencies are second order. The question whether actual markets respond in any of these ways poses theoretical and empirical issues. Regarding theory, the analysis must be more concrete. How does competition work when some consumers are fully rational and others are not? ${ }^{8}$ Regarding empirics, does competition work in the ways that theory suggests?

This article takes a theoretical tack. Section 2 creates a search equilibrium model of competition among firms for naive and sophisticated consumers. ${ }^{9}$ The model addresses two issues: $(a)$ how competition affects the price at which naive contracts are sold and $(b)$ how competition affects the mix of naive and sophisticated contracts the market offers. Section 3 shows that, under plausible conditions, competitive markets will reduce the prices of naive contracts and sometimes will drive naive contracts out altogether. ${ }^{10}$ The conclusion (Section 4) summarizes the results and discusses their normative implications.

A serious normative question should be raised at the outset: is it desirable for competition to drive out contracts intended for the naive? This result would be unfortunate if the normative goal were the maximization of persons' actual preferences, for the preferences of the naive would have been frustrated. A full normative analysis of what markets should do is outside this article's scope, but the conclusion will briefly argue that society should want markets to implement the consumer's ideal preferences-the preferences she would have were she sophisticated-rather than her actual preferences. If this argument persuades,

8. A Coasian analysis would take a broader focus, to ask when cognitive error is best corrected within firms or on markets. Market analysis regarding cognitive error is so undeveloped that it seems productive at this stage to pursue a market inquiry separately.

9. A search model analyzes competition for search goods, which are goods all of whose features the buyer can observe before purchase. Color thus is a search good, while durability is an experience good. This article uses a search model because it is interested in the contracts consumers sign, and a contract, at least in theory, can be read before the consumer commits to buy.

10. DellaVigna and Malmendier (2004) show that a monopolist will offer utilitymaximizing contracts to sophisticated and to error-prone but self-aware consumers, but the monopolist will exploit the naive. They obtain the same results in the competitive case when competition is perfect. Perfect competition, however, requires consumers to have zero search costs: that is, the consumer can costlessly compare the contracts that every firm in the market offers. The analysis below asks how markets perform under the more realistic assumption that it is costly for consumers to search. 
then markets that respond more to the sophisticated than to the naive are performing well. ${ }^{11}$

\section{A SEARCH MODEL}

\subsection{Consumer Types}

Each consumer buys one contract, which is associated with the purchase of a product or the incurring of a financial obligation, or the consumer does not transact. Consumers are partitioned in two ways. First, some consumers do not make errors or do but are aware of their failings. Both consumer types are denoted "sophisticated" because they can correctly match their type to the contracts they buy. Other consumers are in objective circumstances similar to those of the sophisticated consumers but make errors. These consumers, however, are unaware of their penchant to err and so are denoted "naive"; they are more likely than the sophisticated consumers to buy mismatched contracts. There are $B_{\mathrm{s}}$ sophisticated consumers in the market and $B_{\mathrm{n}}$ naive consumers, where $B_{\mathrm{s}}+B_{\mathrm{n}}=B$, the total number of consumers. Consumers also are partitioned according to their shopping behavior. The nonshoppers $-B_{1}$ in number consumers-visit one firm before purchasing. The shoppers$B_{2}$ in number consumers-visit two firms and then purchase the most

11. Akerlof and Yellen (1985, p. 712) make a conjecture that anticipates the results reached here regarding the possible efficacy of markets. They show that while irrational behavior sometimes can have large effects, it is "easy to envision cases in which nonmaximizing behavior by a significant fraction of the population would have only a minor effect on the equilibrium of the system. . . . Suppose, for example, that a significant minority of rational market participants regards two goods or assets as perfect substitutes at a given price ratio; the opinions of such agents is $[s i c]$ apt to dictate the market outcome even in the presence of a substantial fraction of irrational or nonmaximizing agents. Financial markets provide the obvious example." Kluger and Wyatt (2004, p. 995) tested this conjecture by creating a simple double auction market for a security in which the subjects' particular cognitive error is not to update probabilities according to Bayes's law when given new information. They found that when all subjects made this error, the market outcome was inefficient. "However, when markets are made up of both rational (no judgment error) and biased traders, we find the outcome is reversed. . . Competition among . . . bias-free subjects is sufficient to drive prices to correct levels despite the presence of twice as many subjects who exhibit probability judgment errors." This article asks whether competition has similar positive effects in consumer markets for goods or credit. More recently, García, Sangiorgi, and Urošević (2007) argue that in financial markets prices will be set as if all agents are rational, although a positive fraction of agents are naive. This is because, in their model, rational agents adjust their information acquisition strategies to take account of the optimists' behavior. 
attractive of the two contracts they see. ${ }^{12} \mathrm{~A}$ sample size of two is chosen for convenience.

Naive and sophisticated consumers apparently have similar preferences for low prices; both consumer types are assumed to search with the same probability $P .{ }^{13}$ The number of naive shoppers- $P B_{\mathrm{n}}$-is denoted $b_{\mathrm{n}}$, and the number of naive nonshoppers- $(1-P) B_{\mathrm{n}}-$ is denoted $b_{\mathrm{n}}$. Similarly, there are $b_{\mathrm{ss}}$ sophisticated shoppers and $b_{\mathrm{s}}$ sophisticated nonshoppers.

\subsection{Contracts and the Information Structure}

A contract is a set of terms that define a consumer purchase. A firm can sell a high-quality contract, denoted $X_{\mathrm{s}}$, or a low-quality contract, denoted $X_{\mathrm{n}}$. The high-quality contract is intended for the sophisticated consumers because they are more likely than the naive consumers to recognize that the contract is appropriate for their type. The low-quality contract is intended for the naive consumers, whom cognitive bias can cause to make mismatches. ${ }^{14}$ At the beginning of a period, the firm

12. Using a nonsequential search-with a fixed sample size-is an attractive strategy for several reasons. First, it is optimal when the outcome of the search is observed with delay. For example, people often apply for several jobs at once rather than apply for a job and then apply for another only after rejection. Albrecht, Gautier, and Vroman (2006) develop a search equilibrium model to analyze labor markets in which job applicants make a fixed number of applications. Further, when there are fixed costs to shop, it often is best to visit a shopping district, thereby spreading the cost over several store visits. Finally, a fixed sample size search is attractive to risk-averse consumers who do not know the complete price distribution in a market. Using a sequential search in this circumstance may cause consumers to stop searching too soon (they see prices they consider to be low and buy even though there are lower prices) or to stop searching too late (they see prices they consider to be high and continue searching for nonexistent lower prices). The danger of searching too little seems more likely (Einav 2005; Sonnemans 1998).

13. The assumption that all consumers search with the same probability is consistent with results showing that the principal determinant of search intensity in search theory experiments is search costs (Grether, Schwartz, and Wilde 1992).

14. Contracts are assumed to be independent, in the strict sense that the consumers' choice of the naive contract does not affect the payoffs of consumers who choose the sophisticated contract. As an example of how this assumption could be violated, let a lender offer a mortgage with an attractive refinancing option that sophisticated consumers will use optimally (that is, when rates drop substantially) but naive consumers will underuse. The naive consumers' failure to refinance at favorable rates creates a cross subsidy from the naive to the sophisticated. The existence of this subsidy, in turn, could cause sophisticated consumers to reject contract innovations that would benefit everyone but dissipate the subsidy. A similar effect occurs when firms offer a base product and later offer an addon. The willingness of naive consumers to pay monopoly prices for the add-on permits firms to offer the base good at cost or less. The sophisticated consumers benefit by substituting away from the add-on while paying the low price for the base good (Gabaix and 
chooses which type of contract to offer and what price to charge. The firm then knows the naive/sophisticated consumer distribution and the shopper/nonshopper distribution. After a period-a "shopping season"-ends, the firm can revise its contracting strategy. The model below considers only one period.

A firm has no occasion to alter its strategy during a period because, it is assumed, whether a particular consumer is naive or sophisticated, or is a shopper or not, is private information. Regarding the privateinformation assumption, in mass transactions firms cannot distinguish consumers by their analytical ability or penchant to think hard about problems. Also, the relation between easily available demographic data and the presence of bias in particular persons is crude. For example, the evidence now does not support such claims as that consumers who make $\$ 100,000$ per year are less likely to discount hyperbolically than are consumers who make $\$ 50,000$ a year. Similarly, consumers' susceptibility to framing effects is invariant to age (Ronnlund et al. 2005). ${ }^{15}$ Finally, parties do not bargain in the model, so a firm cannot conveniently learn whether consumers who visit it have visited another firm or plan to shop further.

\subsection{Costs and Prices}

There are $Y$ total firms in the market, where $Y_{\mathrm{s}}$ sell the sophisticated contract $X_{\mathrm{s}}$ and $Y_{\mathrm{n}}$ sell the naive contract $X_{\mathrm{n}}\left(Y_{\mathrm{s}}+Y_{\mathrm{n}}=Y\right.$, the total number of firms). Each firm has fixed costs $F_{i}(i=\mathrm{s}$ or n), produces at a constant marginal cost of $c_{i}$ over some range $\left\{0, z_{i}\right\}$, and produces at an infinite marginal cost thereafter $\left(z_{i}\right.$ thus is the firm's capacity constraint). The average cost of offering a contract is $\mathrm{AC}\left(X_{i}\right)=\left(F_{i} / q\right)+c_{i}$, where $q$ is output. The competitive price, which has each firm pricing contracts at an average cost and selling up to capacity, thus is $p_{i}^{*}=$ $\mathrm{AC}_{i}\left(X_{i}\right)\left(z_{i}\right)=\left(F_{i} / z_{i}\right)+c_{i}$. There is free entry, so in equilibrium firms earn zero profits, and no firm can increase its expected profits by changing its price or the type of contract it offers.

Laibson 2006). Few consumer contracts have been identified, however, that permit the kinds of cross subsidization described in this footnote. The independence assumption thus should not materially bias the results reached here.

15. Agarwal et al. (2006, p. 10) report that "the pattern of results [in their credit card study] is broadly similar across the wealthy versus non-wealthy accounts." The assumption that consumer types are private information is a domain assumption. The model does not apply when a firm can learn, on a person-to-person basis, which consumers are naive and which are not. A firm that knows this information will offer exploitative contracts to the naive. 
Contracting costs are assumed to increase with contract quality (that is, it costs the firm more to offer a broad warranty than to offer a narrow warranty). More particularly, the marginal cost of selling contracts is assumed not to vary by contract type: $c_{\mathrm{n}}=c_{\mathrm{s}}=c$. The assumptions that contracting costs are increasing in quality and that marginal costs are the same imply that the fixed costs of offering the high-quality contract exceed the fixed costs of offering the low-quality contract. Consequently, the competitive price of the sophisticated contract $-p_{\mathrm{s}}^{*}$ - exceeds the competitive price of the naive contract- $p_{\mathrm{n}}^{*}$. The fixed-cost assumption is plausible but may be too general. The implications of relaxing it are considered in Section 3.3.

\subsection{Willingness to Pay and Consumer Preferences}

A consumer is said to prefer a contract if she would choose it after seeing both contracts selling at their competitive prices. To understand this concept of a preference, let a sophisticated consumer purchase the contract intended for her, $X_{s}$, at any price up to a common limit price for sophisticated consumers of $l_{\mathrm{s}}$. A consumer will purchase her less preferred contract if the price of her preferred contract is too high. The sophisticated consumer thus will purchase the contract intended for naive consumers, $X_{\mathrm{n}}$, at any price up to a common limit price of $l_{\mathrm{sn}}$. Sophisticated consumers are assumed to have a greater willingness to pay for the sophisticated contract than for the naive contract $\left(l_{\mathrm{s}}>l_{\mathrm{sn}}\right)$. If the same reasoning is used, a naive consumer will purchase $X_{\mathrm{n}}$ at any price up to a common limit price for naive consumers of $l_{\mathrm{n}}$ and will purchase $X_{\mathrm{s}}$ at any price up to a common limit of $l_{\mathrm{ns}}$, where $l_{\mathrm{n}}>l_{\mathrm{ns}}$. A sophisticated consumer also is assumed to have a lower willingness to pay for the naive contract than the naive consumer has $\left(l_{\mathrm{sn}}<l_{\mathrm{n}}\right)$. Similarly, for naive consumers, $l_{\mathrm{ns}}<l_{\mathrm{s}}$. These limit prices are referred to as the consumers' willingness to pay for contract types.

A consumer who sees both contracts will purchase the contract for which her marginal willingness to pay exceeds her marginal cost. To see what is meant, note that the naive consumer would derive a surplus of $l_{\mathrm{n}}-p_{\mathrm{n}}^{*}$ if she purchased $X_{\mathrm{n}}$ at its competitive price and a surplus of $l_{\mathrm{ns}}-p_{\mathrm{s}}^{*}$ if she purchased $X_{\mathrm{s}}$ when it is priced competitively. If the terms are rearranged, this consumer will buy $X_{\mathrm{n}}$ if $l_{\mathrm{n}}-l_{\mathrm{ns}}>p_{\mathrm{n}}^{*}-p_{\mathrm{s}}^{*}$, where the left-hand side of this inequality is the consumer's marginal willingness to pay for the naive contract and the right-hand side is her additional marginal cost. The left-hand side is positive and the right-hand side is negative, so the inequality always is satisfied. The naive consumer thus 
will purchase $X_{\mathrm{n}}$ if she sees both contracts priced competitively. ${ }^{16}$ If the same logic is used, the sophisticated consumer would purchase the sophisticated contract if she saw both contracts priced competitively and $l_{\mathrm{s}}-l_{\mathrm{sn}}>p_{\mathrm{s}}^{*}-p_{\mathrm{n}}^{*}$. Both sides of this inequality are positive, so the inequality may not always hold. A sophisticated consumer who only weakly preferred the sophisticated contract would purchase the competitively priced naive contract if the fixed costs of selling that contract were much below the fixed costs of selling the sophisticated contract. The combination of a weak willingness to pay for a contract and relatively high fixed costs to create and administer it seems uncommon. Therefore, the sophisticated consumer is assumed to prefer $X_{\mathrm{s}}$ when she sees both contracts priced competitively.

\subsection{Switching between Contracts}

In the model, consumers sometimes will purchase their less preferred contract. To see precisely when, consider a naive consumer. She is assumed to reject the naive contract $X_{\mathrm{n}}$ when it is priced such that she would earn at least as much surplus by purchasing $X_{\mathrm{s}}$ at its competitive price. The noncompetitive price for $X_{\mathrm{n}}$ that satisfies this condition is the switching price. If this price is denoted $p_{\mathrm{n}}(a)$, a naive consumer who observes both contract types will buy the sophisticated contract when $l_{\mathrm{ns}}-p_{\mathrm{s}}^{*} \geqslant l_{\mathrm{n}}-p_{\mathrm{n}}(a)$. The left-hand side of this inequality is the naive consumer's surplus from purchasing $X_{\mathrm{s}}$ when it is priced competitively; the right-hand side is the surplus from purchasing $X_{\mathrm{n}}$ at the switching price. Letting this expression be an equality and rearranging terms yields the switching price that would induce naive consumers to buy sophisticated contracts: $p_{\mathrm{n}}(a)=l_{\mathrm{n}}-l_{\mathrm{ns}}+p_{\mathrm{s}}^{*}$. The price at which a sophisticated consumer would switch to $X_{\mathrm{n}}-p_{\mathrm{s}}(a)$-is derived similarly.

This analysis suggests that the degree of exploitation a market can sustain is decreasing in consumer sophistication. For example, consumers may make fewer mistakes regarding the warranty term than regarding the prepayment penalty term because consumers experience product de-

16. This result follows from assuming that the naive consumer has a greater willingness to pay for the contract intended for her than for the contract intended for the sophisticated

consumer, and the fixed costs of offering sophisticated contracts exceed the fixed costs of offering naive contracts. 
fects more commonly than they prepay loans. ${ }^{17}$ The less naive a consumer is, the greater will be her willingness to pay for a sophisticated contract; she will (partly) recognize that contract's virtues. Formally, $l_{\mathrm{ns}}$ will approach $l_{\mathrm{n}}$, so $p_{\mathrm{n}}(a)$ will be close to the competitive price for $X_{\mathrm{n}}$ of $p_{\mathrm{n}}^{*}$. In turn, when $p_{\mathrm{n}}(a)$ is low, firms that price $X_{\mathrm{n}}$ noncompetitively risk losing the business of naive shoppers.

\subsection{The Firm's Comparative Advantage}

A firm is said to have a comparative advantage at selling a contract type if the firm needs fewer customers to break even-to recover its fixed costs-selling that contract type at its limit price than selling the other type at its limit price. A firm breaks even at the limit when its net revenue on sales equals its fixed costs: that is, when $\lambda_{i}\left(l_{i}-c\right)=F_{i}$, where $\lambda$ is the number of customers the firm expects to have when it prices at the limit. If the terms are rearranged,

$$
\lambda_{i}=\frac{F_{i}}{l_{i}-c} .
$$

Thus, a firm would have a comparative advantage, denoted $\lambda_{\mathrm{s}}$, at selling the sophisticated contract $X_{\mathrm{s}}$ if

$$
\lambda_{\mathrm{s}}=\frac{F_{\mathrm{s}}}{l_{\mathrm{s}}-c_{\mathrm{s}}}<\lambda_{\mathrm{n}}=\frac{F_{\mathrm{n}}}{l_{\mathrm{n}}-c_{\mathrm{n}}} .
$$

As will become apparent, when firms have a comparative advantage at selling one contract type, the market is less likely to offer the other contract type.

\section{ANALYSIS}

\subsection{Pricing Decisions}

The heuristic is to assume that firms sell only the naive contract priced competitively and then to ask whether this equilibrium is robust to de-

17. Some biases moderate with experience. For example, Van den Steen (2004, p. 1141) states that the overconfidence "bias also increases in a mean-preserving spread of the distribution of prior beliefs, but it tends to disappear with sufficient experience with the particular choice problem." Agarwal et al. (2008) show that the likelihood that a consumer will pay a late fee under a credit card contract falls if the consumer has paid a late fee in the past, and Agarwal et al. (2006, p. 5) find that consumers "who made larger errors in their initial [credit card] contract choice were more likely subsequently to switch to the optimal contract." Also, experience substantially improves peoples' ability to do Baysian reasoning (Harrison 1994; Camerer 1990). 
viations. Two related factors influence a firm's decision to deviate in the price dimension. First, the firm will trade off the increased revenue from a supracompetitive price against the reduction in demand from consumers who shop. Second, the firm must recover its fixed costs; the higher these are, the more customers the firm needs to break even, so the more difficult it is to sustain high prices. The demand and fixed-cost factors imply that three prices can exist in equilibrium:

i. $\quad X_{\mathrm{n}}$ at $p_{\mathrm{n}}^{*}$ : This is the competitive equilibrium price.

ii. $X_{\mathrm{n}}$ at $l_{\mathrm{sn}}$ : This is the sophisticated consumer's willingness to pay for the naive contract.

iii. $X_{\mathrm{n}}$ at $l_{\mathrm{n}}$ : This is the limit price for the naive contract.

A firm that deviated to the limit price would sell only to naive nonshoppers. The naive shoppers would see the contract $X_{\mathrm{n}}$ selling elsewhere at its competitive price and buy it. The deviant firm would not sell to sophisticated shoppers. They would also see $X_{\mathrm{n}}$ priced at $p_{\mathrm{n}}^{*}$, which is below the price for the naive contract that will induce a sophisticated consumer to switch. ${ }^{18}$ The firm also would not sell to sophisticated nonshoppers because they have a lower willingness to pay for the naive contract than the naive consumers have (that is, $l_{\mathrm{sn}}<l_{\mathrm{n}}$ ). Therefore, only naive nonshoppers would purchase $X_{\mathrm{n}}$ at its limit price of $l_{\mathrm{n}}$.

The firm would not deviate from the competitive equilibrium if a deviation would earn it a nonpositive profit. This equilibrium condition is expressed as

$$
\left(l_{\mathrm{n}}-c\right) \frac{b_{\mathrm{n}}}{Y}-F_{\mathrm{n}} \leqslant 0
$$

The first term on the left-hand side of this expression is the surplus the firm would earn from the deviation (limit price less marginal cost) times the expected demand from naive nonshoppers. The expression can be written as

$$
\frac{b_{\mathrm{n}}}{Y} \leqslant \frac{F_{\mathrm{n}}}{l_{\mathrm{n}}-c}=\lambda_{\mathrm{n}}
$$

A deviation to the highest price for the naive contract thus would not occur if naive consumers comparison shop $\left(b_{\mathrm{n}}\right.$ is low $)$ and if the firm has a relatively low comparative advantage at offering the naive contract $\left(\lambda_{n}\right.$ is high). To understand the second condition, note that the firm would

18. To show this, the price that would induce the sophisticated consumer to switch to $X_{\mathrm{n}}$ is $p_{\mathrm{s}}(a)=l_{\mathrm{s}}-l_{\mathrm{sn}}+p_{\mathrm{n}}^{*}$. That $l_{\mathrm{s}}>l_{\mathrm{sn}}$ implies that $p_{\mathrm{n}}^{*}<p_{\mathrm{s}}(a)$. 
have a low comparative advantage if naive consumers have a low willingness to pay for the naive contract $\left(l_{\mathrm{n}}\right.$ is low) or if the fixed costs of selling exploitative contracts are high $\left(F_{\mathrm{n}}\right.$ is high). The firm gains less from charging the limit price when the limit is low, and the firm needs more naive nonshoppers to recover its fixed costs when those costs are high.

No deviation to prices between $l_{\mathrm{n}}$ and $l_{\mathrm{sn}}$, the limit price of a sophisticated consumer for the naive contract, would be profitable. At any such price, only naive nonshoppers would purchase. Since the firm could sell to these consumers at the higher $l_{\mathrm{n}}$ price, the firm would either charge the limit if that deviation were profitable or consider deviating to $l_{\mathrm{sn}}$. The firm would then sell to both types of nonshoppers but would not sell to any shoppers; both shopping types would prefer $X_{\mathrm{n}}$ at $p_{\mathrm{n}}^{*}$ to $X_{\mathrm{n}}$ at $l_{\mathrm{sn}} \cdot{ }^{19}$ A deviation to $l_{\mathrm{sn}}$ would be unprofitable if, after rearranging terms,

$$
\frac{B_{1}}{Y} \leqslant \frac{F_{\mathrm{n}}}{\left(l_{\mathrm{sn}}-c\right)} .
$$

The left-hand side of equation (2) is larger than the left-hand side of equation (1), which implies that this deviation is more likely. However, $l_{\mathrm{sn}}<l_{\mathrm{n}}$, so the right-hand side of equation (2) is larger than the righthand side of equation (1). If sophisticated consumers have a low willingness to pay for naive contracts $\left(l_{\mathrm{sn}}\right.$ is small), then the demand effect will dominate: the firm will have too few customers to recover its fixed costs when it charges $l_{\mathrm{sn}}$.

No deviation to prices between $l_{\mathrm{sn}}$ and $p_{\mathrm{n}}^{*}$ would be profitable. To see why, consider a deviation to a price $q$ where $p_{\mathrm{n}}^{*}<q<l_{\mathrm{sn}}$. The firm would continue to sell to both types of nonshoppers at price $q$, but the shoppers would see $X_{\mathrm{n}}$ at $p_{\mathrm{n}}^{*}$ and buy it. Thus, the deviation would not increase the firm's demand but would reduce its profit per sale. This logic applies to any price in the interval between $l_{\mathrm{sn}}$ and $p_{\mathrm{n}}^{*}$.

Two or more of these equilibrium prices could coexist. The analysis has asked whether a single firm would deviate from a competitive equilibrium that has $X_{\mathrm{n}}$ sold at $p_{\mathrm{n}}^{*}$. A firm that deviates to the limit of $l_{\mathrm{n}}$ would sell only to naive nonshoppers. There may be enough of them to sustain deviations by a subset of firms but not by all. Similarly, a firm that deviates to $l_{\mathrm{ns}}$ would sell only to nonshoppers, and there may not be enough of them to sustain this deviation by every firm. In such cases, 
there will be price dispersion in equilibrium: two or three prices could coexist. $^{20}$

The analysis of the firm's pricing decision can be summarized in this way:

Proposition 1. When every firm sells the naive contract $X_{\mathrm{n}}$, three equilibrium prices are possible: (i) $p_{\mathrm{n}}^{*}$, the competitive price, (ii) $l_{\mathrm{sn}}$, the limit price of sophisticated consumers for the naive contract, and (iii) $l_{\mathrm{n}}$, the limit price of naive consumers for the naive contract.

Remark 1. Deviations to noncompetitive prices are less likely if $(a)$ the ratio of sophisticated consumers to total consumers is high, $(b)$ the willingness of sophisticated consumers to pay for naive contracts is low, (c) the willingness of naive consumers to pay for naive contracts is low, (d) the ratio of shoppers to total consumers is high, and $(e)$ the fixed costs of offering naive contracts are high. The presence of sophisticated consumers helps the naive in two ways. First, some sophisticated consumers shop. Second, sophisticated consumers have a lower willingness to pay for the naive contract than the naive consumers have. Both factors exert a downward pressure on the prices firms can charge for $X_{\mathrm{n}}$.

Remark 2. Competition is beneficial in two ways. First, competition will ameliorate or eliminate the redistribution of wealth from consumers to firms. The lower that firms are forced to price $X_{\mathrm{n}}$, the greater is the surplus consumers realize from buying it. Second, when firms earn rents from noncompetitive pricing, new firms will enter the market to compete for those rents. As a consequence, though all firms come to earn zero pure profits, the market will have too many firms. This inefficiency is reduced as market pricing becomes more competitive because then fewer firms will

20. Two price equilibria were shown to exist in the well-known Salop and Stiglitz (1977) search model. Experimental evidence confirming predictions of search models that price dispersion exists in equilibrium when goods are homogenous but not all consumers are informed is in Morgan, Orzen, and Sefton (2006), Cason and Datta (2006), and Grether, Schwartz, and Wilde (1992). Also, Kim, Dunn, and Mumy (2005) test a credit card model in which all consumers are rational and some search more than others. They found that the searchers obtained lower interest rates. The extent to which the credit card market today is competitive is controversial. Ausubel (1991) argued that the market was noncompetitive because, using 1980s data, interest rates on credit cards were relatively insensitive to banks' cost of funds. More recent data show that this sensitivity has increased substantially (Brown and Plache 2006, p. 78). However, adverse selection makes it difficult for consumers with high credit card balances to switch to firms offering better rates, though this effect has moderated in recent years (Calem, Gordy, and Mester 2006). This article takes no position on the competitiveness of particular markets. 
enter. Finally, the model assumes for convenience that consumers engage in the minimum amount of search; shoppers visit only two firms. If consumers search more extensively, the beneficial effects of competition would be enhanced.

Remark 3. The ideal, among legal scholars, is the "dickered term": the portion of the agreement whose content is codetermined. Dickering has less appeal in consumer markets if firms can use the bargaining process to learn whether consumers are naive and whether they shop. Such firms could then offer exploitative contracts to the naive and the less diligent. In contrast, in the model here the selling side chooses every term, but firms cannot identify particular consumers by type. Proposition 1 thus suggests that consumers can be better off with anonymity plus competition than with the opportunity to bargain with firms over terms.

\subsection{Contracting Decisions}

The next issue is whether the competitive equilibrium of $X_{\mathrm{n}}$ at $p_{\mathrm{n}}^{*}$ is robust to deviations by firms offering the sophisticated contract $X_{\mathrm{s}}$. Such a firm would sell to a different customer mix, but it would also face the same trade-off between higher profits per sale and the consequent reduction in demand. Again, three prices for $X_{\mathrm{s}}$ can exist in equilibrium:

i. $X_{\mathrm{s}}$ at $p_{\mathrm{s}}^{*}$ : This is the competitive price for $X_{\mathrm{s}}$.

ii. $\quad X_{\mathrm{s}}$ at $l_{\mathrm{ns}}$ : This is naive consumers' willingness to pay for the sophisticated contract.

iii. $X_{\mathrm{s}}$ at $l_{\mathrm{s}}$ : This is the limit price for $X_{\mathrm{s}}$.

A firm that deviated to $l_{\mathrm{s}}$ would serve only sophisticated nonshoppers. The firm would not sell to naive shoppers because their other draw would be from a firm selling $X_{\mathrm{n}}$ priced competitively. The firm also would not sell to naive nonshoppers because their willingness to pay for the sophisticated contract is less than the willingness to pay of sophisticated consumers for that contract (that is, $l_{\mathrm{ns}}<l_{\mathrm{s}}$ ). Finally, the firm would not sell to sophisticated shoppers because their other draw also would be from a firm selling $X_{\mathrm{n}}$ at $p_{\mathrm{n}}^{*}$, which is below the sophisticated consumer's switching price. If the logic above is used, a deviation from selling the naive contract at $p_{\mathrm{n}}^{*}$ to selling the sophisticated contract at its limit price would earn nonpositive profits if

$$
\frac{b_{\mathrm{s}}}{Y} \leqslant \frac{F_{\mathrm{s}}}{l_{\mathrm{s}}-c} \leqslant \lambda_{\mathrm{s}} .
$$

An equilibrium in which some firms sold $X_{\mathrm{n}}$ at $l_{\mathrm{n}}$ while other firms 
sold $X_{\mathrm{s}}$ at $l_{\mathrm{s}}$ would not exist if firms would earn negative profits selling $X_{\mathrm{n}}$ at $l_{\mathrm{n}}$ but would earn positive profits selling $X_{\mathrm{s}}$ at $l_{\mathrm{s}}$. To see when this could occur, compare equations (1) and (3). The fixed costs of selling the sophisticated contract are assumed to exceed the fixed costs of selling the naive contract $\left(F_{\mathrm{s}}>F_{\mathrm{n}}\right)$. Therefore, equation (3) could be violated (deviations to $X_{\mathrm{s}}$ at its limit would be profitable), but equation (1) could be satisfied if there are sufficiently more sophisticated nonshoppers than naive nonshoppers or if the sophisticated consumers had a sufficiently greater willingness to pay for the contract intended for them than the naive consumers had for the contract intended for them.

No deviation to any price in the interval between $l_{\mathrm{s}}$ and $l_{\mathrm{ns}}$ would be profitable. The deviant firm would sell only to sophisticated nonshoppers at any such price, and it could do better selling to them at $l_{s}$. If the firm deviated to $l_{\mathrm{n}}$, the willingness to pay of a naive consumer for the sophisticated contract, the firm would sell to every nonshopper who visited it. If the logic above is used, this deviation would earn nonpositive profits if

$$
\frac{B_{1}}{Y} \leqslant \frac{F_{\mathrm{s}}}{l_{\mathrm{ns}}-c} .
$$

An intermediate contract quality deviation would be unique when firms sell $X_{\mathrm{s}}$ at $l_{\mathrm{ns}}$ but do not sell $X_{\mathrm{n}}$ at $l_{\mathrm{sn}}$. The left-hand side of equations (2) and (4) are identical (only nonshoppers are customers for intermediate deviations). As a consequence, the assumption that $F_{\mathrm{n}}<F_{\mathrm{s}}$ will preclude this equilibrium unless naive consumers are sufficiently more willing to pay for sophisticated contracts than sophisticated consumers are willing to pay for naive contracts (that is, if $l_{\mathrm{ns}}$ were sufficiently greater than $\left.l_{\mathrm{sn}}\right)$.

The firm would only sell to nonshoppers at any price in the interval between $l_{\mathrm{ns}}$ and $p_{\mathrm{s}}^{*}$. The firm thus would either charge the higher $l_{\mathrm{ns}}$ price or deviate downward to the competitive price. At $p_{\mathrm{s}}^{*}$, the firm would sell to every sophisticated consumer who visits it. Sophisticated nonshoppers would buy $X_{\mathrm{s}}$ because it is below their limit price. Sophisticated shoppers would buy $X_{\mathrm{s}}$ because their other draw would be from a firm selling $X_{\mathrm{n}}$ at $p_{\mathrm{n}}^{*}$, and each consumer type prefers the contract intended for her when both contracts are priced competitively. The firm would also sell to naive nonshoppers who visit it because $p_{s}^{*}$ is below the switching price for these consumers of $p_{\mathrm{n}}(a)$. The firm would not sell to naive shoppers because they would also see $X_{\mathrm{n}}$ at its competitive price. Therefore, the set of firms offering $X_{\mathrm{n}}$ at $p_{\mathrm{n}}^{*}$ shrinks as the ratio of sophisticated con- 
sumers to total consumers and the ratio of shoppers to nonshoppers both increase. It is possible for no or few firms to offer the naive contract even though there are naive customers for it.

This analysis of contracting decisions is summarized in the following:

Proposition 2. Competition can cause equilibria to vanish in which firms sell only naive contracts. In such cases, either the market will offer both contract types or only sophisticated contracts will trade. The "good" outcomes are more likely to occur when firms have a comparative advantage at selling sophisticated contracts. They also are more likely to occur if there are relatively many sophisticated consumers, if consumers of both types often shop, and if naive consumers have a relatively high willingness to pay for sophisticated contracts.

Remark 4. The analysis asked whether deviations to the sophisticated contract were possible when every firm is pricing the naive contract competitively. Deviations are more likely when firms price $X_{\mathrm{n}}$ monopolistically. If a substantial number of sophisticated nonshoppers are present, firms would do better selling $X_{\mathrm{s}}$ at $l_{\mathrm{ns}}$ than selling $X_{\mathrm{n}}$ at $l_{\mathrm{n}}$ unless the fixed costs of selling the sophisticated contract greatly exceeded the fixed costs of selling the naive contract or the willingness of naive consumers to pay for sophisticated contracts was quite low. ${ }^{21}$

Remark 5. Proposition 2 is a possibility result. Competition can reduce the fraction of naive contracts and sometimes eliminate them. Proposition 2 thus should be taken to tell decision makers to investigate the status of particular markets before intervening on the ground that $\operatorname{cog}$ nitive error exists.

Remark 6. A number of biases, such as overconfidence and the endowment effect (List 2003), moderate with experience. This fact suggests that naivete is less common or weaker in markets in which consumers buy or borrow frequently. The less naive a consumer is, the lower is her willingness to pay for the naive contract and the higher is her willingness

21. If equations (1) and (4) are compared, firms would do better selling $X_{\mathrm{s}}$ at $l_{\mathrm{ns}}$ than $X_{\mathrm{n}}$ at $l_{\mathrm{n}}$ when $\left[B_{1}\left(l_{\mathrm{ns}}-c\right)-b_{\mathrm{n}}\left(l_{\mathrm{n}}-c\right)\right] / Y>F_{\mathrm{s}}-F_{\mathrm{n}}$. The term $B_{1}$ is the total number of nonshoppers, while $b_{\mathrm{n}}$ is the total number of naive nonshoppers. When there are a substantial number of sophisticated nonshoppers, $B_{1}$ will be much larger than $b_{\mathrm{n}}$. Therefore, firms would do better selling $X_{\mathrm{s}}$ than $X_{\mathrm{n}}$ when the fixed costs are close or when the willingness to pay of the groups is close. 
to pay for the sophisticated contract. Common transactions thus are less likely to be conducted under naive contracts than are rare transactions.

\subsection{Revisiting Fixed Costs}

This article assumes that the marginal costs of selling contract types are equal and that the firm's contracting cost is increasing in contract quality. These assumptions imply that the fixed costs of selling the sophisticated contract exceed the fixed costs of selling the naive contract. Reversing the fixed-cost assumption thus would imply that contract cost is decreasing in contract quality. If this is so, the market is more likely to offer both contract types or only the sophisticated contract. Intuitively, when $X_{\mathrm{n}}$ is priced at or above $X_{\mathrm{s}}$, a consumer who sees both contracts will buy $X_{\mathrm{s}}$. The sophisticated consumer prefers $X_{\mathrm{s}}$ and the naive consumer prefers a higher to a lower quality contract when the higher quality contract has a lower price. For example, a consumer who incorrectly thinks she needs a narrow warranty would buy a broad warranty if the marginal premium were zero or negative. This intuition underlies the fact that if $F_{\mathrm{s}}<F_{\mathrm{n}}$, firms are more likely to have a comparative advantage at selling the sophisticated contract. When the comparative advantage runs in this direction, deviations from equilibria in which every firm offers $X_{\mathrm{n}}$ to equilibria in which some, or all, firms offer $X_{\mathrm{s}}$ will be more common (see proposition 2). Thus, it is worth asking whether the fixed costs of selling sophisticated contracts always exceed the fixed costs of selling naive contracts.

The fixed costs of selling a contract are primarily the costs of creating a system to administer it, and these costs could vary inversely with a contract's quality. Some low-quality contracts truncate consumers' postpurchase contact with the firm relative to high-quality contracts of the same type; other low-quality contracts expand the consumers' postpurchase contact with the firm relative to sophisticated contracts of the same type. As examples, a low-quality warranty contract truncates postpurchase contact relative to a high-quality warranty contract. The less the warranty covers, the fewer are the claims consumers can make. Thus, the fixed costs of creating a system to respond to warranty claims should be higher when the firm makes a broad warranty than when it makes a narrow warranty. In the former case, the firm must be prepared to adjudicate a nontrivial number of claims and to repair or replace defective items. In the latter case, the firm will tell many consumers to go away. Hence, higher quality warranty contracts have higher fixed costs than do lower quality warranty contracts. 
Low-quality debt contracts expand postpurchase contact relative to high-quality debt contracts, however. Low-quality debt contracts-naive contracts-are disproportionally sold to consumers in relatively disadvantageous economic circumstances and contain harsh default terms, such as broad security interests and high late fees. Firms that sell lowquality debt contracts thus are likely to have extensive postloan contacts with their borrowers: to dun or sue them, to repossess, to participate in a bankruptcy. Firms that sell high-quality debt contracts will usually just process payments. Thus, the lower the quality of a debt contract, the greater will be the fixed costs of selling it. The warranty transaction illustrates a contract that is truncating, while the lending transaction illustrates a contract that is expanding. The reasoning here suggests that $F_{\mathrm{s}}>F_{\mathrm{n}}$ is more likely for truncating contracts and $F_{\mathrm{s}}<F_{\mathrm{n}}$ is more likely for expanding contracts. As a consequence, there may be a higher social payoff to regulating warranty markets on cognitive-error grounds than to regulating credit markets on those grounds.

This conclusion should be tentatively held. The preliminary analysis here is meant only to show that a firm's contracting costs may sometimes decrease with the quality of the contracts it offers. Contract regulation thus should be sensitive to context.

\section{CONCLUSION}

\subsection{Summary}

Market populations commonly are heterogenous. Some consumers are sophisticated; they either do not make cognitive errors or are error prone but self-aware. Other consumers are naive; they are error prone but think they are not. When firms compete, contracts intended for the naive-naive contracts-may still exist, but they are unlikely to be sold at supracompetitive prices. Also, some firms will offer contracts intended for the sophisticated. The likelihood that markets will generate normatively desirable outcomes is increasing in the number of sophisticated consumers, the penchant of both sophisticated and naive consumers to search for the contracts they like, sophisticated consumers' willingness to pay for sophisticated contracts, and the lower the fixed costs are of creating sophisticated contracts relative to the fixed costs of creating naive contracts. Good outcomes also are more likely when naive consumers have a low willingness to pay for contracts intended for them and a consequent relatively high willingness to pay for the sophisticated 
contracts. Pathological cases are possible in which only naive contracts are traded though sophisticated consumers exist, but there also are plausible cases in which both contract types, or only the sophisticated type, are traded.

\subsection{Normative Issues}

Increasing the difficulty of purchasing naive contracts or driving them out altogether are morally problematic options. If naive consumers do not lose their errors, they must experience welfare losses when competition causes their preferred contracts to disappear. ${ }^{22}$ There are two arguments, briefly sketched here, that these losses should not count. The first argument is in a Rawlsian vein and goes like this: Consider a person who initially knows only that she will be a consumer during her adult life. She is then told to assume the following: $(a)$ when she is to make market purchases, she may be naive regarding some or all transactions, or she may be sophisticated regarding some or all transactions; $(b)$ when she is sophisticated, she will purchase the sophisticated contract, if given a choice, because that contract would maximize her expected monetary return; and $(c)$ her consumption choices affect only herself. Assumption $b$ implies that she would have more lifetime wealth if she turned out to be sophisticated than if she turned out to be naive. Assumption $c$ implies that she could not benefit other naive consumers if she herself turned out to be naive or chose to act as if she were. The three assumptions taken together thus imply that the consumer would prefer the market to respond only to sophisticated preferences.

As to the realism of the last two assumptions, sophisticated contracts generally maximize a consumer's expected wealth relative to naive contracts. Thus, the right debt contract reduces the consumer's bankruptcy risk while the wrong one may increase it, and the right warranty contract reduces the risk that the consumer will have to pay the full price for a defective product while the wrong warranty contract leaves that risk relatively untouched. Assumption $b$ thus seems correct. Assumption $c$ also holds because, in the mass markets considered here, a consumer's choice of a naive contract would not materially increase the availability

22. This is a familiar problem in utilitarian theory. Williams $(1985$, p. 88$)$ thus argued that government can reduce utility if it implements idealized preferences but persons never come to have those preferences. 
of that contract for other consumers. Markets, that is, restrict the effect of pursuing altruistic preferences to the expression of opinion. ${ }^{23}$

Original position arguments rest on the premise that persons in the original position are relevantly alike. The argument here rests on the same premise. It supposes everyone to prefer more to less, ceteris paribus, and contends that in large markets the ceteris paribus condition holds.

The second argument for counting only consumers' ideal preferences is more directly utilitarian. It claims, simply, that the preferences a utilitarian should sum must be worth summing. There can be considerable controversy as to which preferences belong in the appropriately summable set, but no one has successfully argued for the inclusion of irrational preferences.

\subsection{Policy Responses}

Section 1.2 suggested that banning naive contracts is problematic. A naive contract reflects a mismatch between a consumer's type and the contract she prefers. Consumer types are difficult for decision makers to observe, however, and so what appear to be mismatches may not be. For example, a narrow warranty may be preferred by a consumer in consequence of her excessive optimism or overconfidence, but it also may be preferred by a sophisticated consumer who has an opportunity to self-insure. Similarly, a credit card contract that requires no initial payment, whose rate increases with time, and that has harsh default fees may reflect a mismatch if bought by a consumer with excessive presentbased preferences or an unstable employment situation. The same contract may be appropriate for a sophisticated consumer who correctly

23. The view that persons hold altruistic preferences in economic environments seems based largely on play in experimental demand games, in which demanders choose a smaller share of the sum the players are to divide than the payoff a demander's power in the game could command. Competing explanations of the phenomenon exist, however. The demander knows the payoff of the other player and knows that she can entirely determine that payoff. That the demander has perfect knowledge and complete power supports either of two inferences about her behavior: the demander is altruistic or she fears rejection of greedy offers. Schmitt (2004) and Bandiera, Baranky, and Rasul (2005) support the latter interpretation, as does Camerer (2003, p. 115), who summarizes studies showing that when persons play market games, where they do not know other players' payoffs and cannot affect those payoffs, persons maximize their own utility. In another vein, Brenner and Vriend (2006) argue that demanders' proposals are high because it takes them a very long time to learn what the expected-payoff-maximizing offer is. The most recent real-world study apparently is List (2006, pp. 5-6), which reports that "though the data collected from oneshot laboratory experiments suggest that social preferences are quite important among the agents, parallel treatments in the field suggest that such effects have minimal influence in naturally occurring transactions." 
expects to borrow little and to repay promptly. In addition, naive contracts may be good buys for everyone when they are competitively priced and the better contracts are priced monopolistically. This reasoning suggests that banning contracts is unlikely to be Pareto improving.

A market is performing badly, however, when identical contracts trade at widely different prices. For example, if $X_{\mathrm{s}}$ trades at both $p_{\mathrm{s}}^{*}$ and $l_{\mathrm{s}}$, then an insufficient number of consumers comparison shop. The two standard remedies to facilitate comparison shopping are to require common terms in consumer contracts to be cast in standard forms, which will facilitate comparisons, and to require the language in those forms to be accessible to the average reader, which will increase comprehension and thus probably increase the perceived need to shop. Both remedies are in insufficient use today.

A third market-improving response is to respond directly to the possible existence of bias. For example, a credit card company could be required to present consumers with a short description of default rates together with a statement that not every borrower can be above average (that consumers are better advised to consider themselves average than good). Because some persons are better able to absorb narrative than to evaluate statistics, an alternative disclosure mode would require firms to provide consumers with scenario information: stories about persons who rolled up excessive late fees or who incurred so much debt that bankruptcy became their best option. Either form of disclosure could reduce consumer naivete by moderating any overconfidence bias. ${ }^{24}$ Statesupplied workshops on good lending and purchasing behavior may be helpful. ${ }^{25}$ Finally, actively involving consumers in a task, such as by requiring them to answer questions about the task before performing it, improves their ability to process relevant information (Natter and Barry 2005). ${ }^{26}$ When naivete falls, market performance improves.

A less promising policy response is to attempt directly to correct disadvantaging biases. Apart from consumer education in schools, this response is difficult to implement. Because biases may offset, the task of bias correction makes great informational demands on the decision maker. As an example, persons who overweight the present may choose

24. Jolls and Sunstein (2006) discuss the need for and the potential efficacy of providing consumers with information of this type.

25. Bertrand, Mullainathan, and Shafer (2006) provide helpful suggestions along this line.

26. Whether it will be practical often to involve consumers in purchasing tasks seems unknown. 
suboptimal effort levels when pursuing projects with delayed payoffs. A person who is excessively confident in her ability to control outcomes, however, may overcome this bad incentive if her misplaced optimism causes her to overrate the probability of success (Besharov 2004). ${ }^{27}$ When offsetting errors are welfare enhancing, correcting one error must be welfare reducing. This suggests that the task of bias correction is best conducted holistically. In addition, many people use self-protective strategies that sometimes work but also may over- or undershoot the mark. ${ }^{28}$ This situation, too, can make the directionality of error difficult for decision makers to assess and thus complicates the task of correction. It may be easier to improve markets than people.

\section{REFERENCES}

Agarwal, Sumit, Souphala Chomsisengphet, Chunlin Liu, and Nicholas S. Souleles. 2006. Do Consumers Choose the Right Credit Contract? Working Paper No. 2006-11. Federal Reserve Bank of Chicago, Chicago.

Agarwal, Sumit, John C. Driscoll, Xavier Gabaix, and David Laibson. 2008.

27. Consistent with this view, more optimistic people work harder (Puri and Robinson 2007), and overconfidence helps to overcome anxiety about whether one can do a task (Compte and Postlewaite 2004). Also, overconfidence may flaw performance in financial markets, but many persons adopt protective personal strategies that permit them to do well (Biais et al. 2005). Similarly, pessimistic consumers who make overly high projections of future consumption needs may not undersave (Rabin 1999), and the self-serving bias, to the extent it exists, may be adaptive (Kaplan and Ruffle 2004). See also Krueger and Funder (2004, p. 319): "As soon as one asks whether changes in one bias may result in changes in others, one moves toward a more comprehensive model."

28. Persons sometimes attempt to overcome biases through internal systems of control. For example, considerable evidence exists that a person forms her self-image by inducting the kind of person she is from her past actions. Because persons have imperfect recall (they cannot fully evaluate the wisdom of past choices), they develop personal rules to guide behavior. It is easier to recall whether one violated a rule. The cost to a person of violating a rule may be large: missing a scheduled exercise day will reduce fitness only by a little but may contribute substantially to the person's view that she actually is slothful (Kim 2006). For evidence that persons respond to this concern by creating personal rules, and then may adhere to these rules too rigidly, see Soman and Cheema (2004). Relevant here is their evidence that persons who fear they suffer from weakness of will may develop savings rules that they are reluctant to break. Benabou and Tirole (2004, p. 850, emphasis in original) formalize this idea in a model that shows, among other things, "that agents with hyperbolic discounting can actually behave as though they overweighed the future rather than the present." Persons also use mental accounting, assigning expenses to separate categories and keeping budgets for each category. This strategy, too, can ameliorate weakness of will but may yield either rigidities or, when an expense can be assigned to more than one category, strategic overspending (Cheema and Soman 2006). 
156 / THE JOURNAL OF LEGAL STUdies / VOLUME 37 (1) / JANUARY 2008

Learning in the Credit Card Market. NBER Working Paper No. W13822. National Bureau of Economic Research, Cambridge, Mass.

Agnew, Julie R. 2006. Do Behavioral Biases Vary across Individuals? Evidence from Individual Level 401(k) Data. Journal of Financial and Quantitative Analysis 41:939-62.

Akerlof, George A., and Janet L. Yellen. 1985. Can Small Deviations from Rationality Make Significant Differences to Economic Equilibria? American Economic Review 75:708-20.

Albrecht, James, Pieter A. Gautier, and Susan Vroman. 2006. Equilibrium Directed Search with Multiple Applications. Review of Economic Studies 73: 869-91.

al-Nowaihi, Ali, and Sanjit Dhami. 2006. A Note on the Lowenstein-Prelec Theory of Intertemporal Choice. Mathematical Social Sciences 52:99-108.

Ausubel, Lawrence M. 1991. The Failure of Competition in the Credit Card Market. American Economic Review 81:50-81.

Bandiera, Oriana, Iwan Barankay, and Imran Rasul. 2005. Social Preferences and the Response to Incentives: Evidence from Personal Data. Quarterly Journal of Economics 120:917-62.

Benabou, Roland, and Jean Tirole. 2004. Willpower and Personal Rules. Journal of Political Economy 112:848-86.

Bertrand, Marianne, Sendhil Mullainathan, and Eldar Shafer. 2006. Behavioral Economics and Marketing in Aid of Decision Making among the Poor. Journal of Public Policy and Marketing 25:8-23.

Besharov, Gregory. 2004. Second-Best Considerations in Correcting Cognitive Biases. Southern Economic Journal 71:12-20.

Biais, Bruno, Denis Hilton, Karine Mazurier, and Sebastian Pouget. 2005. Judgmental Overconfidence, Self-Monitoring, and Trading Performance in an Experimental Financial Market. Review of Economic Studies 72:287-312.

Brenner, Thomas, and Nicolaas J. Vriend. 2006. On the Behavior of Proposers in Ultimatum Games. Journal of Economic Behavior and Organization 61: 617-31.

Brown, Tom, and Lacey Plache. 2006. Playing with Plastic: Maybe Not So Crazy. University of Chicago Law Review 73:63-86.

Calem, Paul S., Michael B. Gordy, and Loretta J. Mester. 2006. Switching Costs and Adverse Selection in the Market for Credit Cards: New Evidence. Journal of Banking and Finance 30:1653-85.

Camerer, Colin F. 1990. Do Markets Correct Biases in Probability Judgment? Evidence from Market Experiments. Pp. 126-72 in Advances in Behavioral Economics, edited by Leonard Green and John Kagel. Norwood, N.J.: Ablex.

- 2003. Behavioral Game Theory. Princeton, N.J.: Princeton University Press.

Campbell, John Y. 2006. Household Finance. Journal of Finance 61:1553-1604.

Cason, Timothy A., and Shakun Datta. 2006. An Experimental Study of Price 
Dispersion in an Optimal Search Model with Advertising. International Journal of Industrial Organization 24:639-65.

Cheema, Amar, and Dilip Soman. 2006. Malleable Mental Accounting: The Effect of Flexibility on the Justification of Attractive Spending and Consumption Decisions. Journal of Consumer Psychology 16:33-44.

Chiappe, Dan, and Kevin MacDonald. 2005. The Evolution of Domain-General Mechanisms in Intelligence and Learning. Journal of General Psychology 132:5-40.

Compte, Oliver, and Andrew Postlewaite. 2004. Confidence-Enhanced Performance. American Economic Review 94:1536-57.

Dasgupta, Partha, and Eric Maskin. 2005. Uncertainty and Hyperbolic Discounting. American Economic Review 95:1290-99.

DellaVigna, Stefano, and Ulrike Malmendier. 2004. Contract Design and SelfControl: Theory and Evidence. Quarterly Journal of Economics 119: 353-402.

Einav, Liran. 2005. Informational Asymmetries and Observational Learning in Search. Journal of Risk and Uncertainty 30:241-59.

Frederick, Shane, George Lowenstein, and Ted O’Donaghue. 2002. Time Discounting and Time Preference: A Critical Review. Journal of Economic Literature 40:351-401.

Gabaix, Xavier, and David Laibson. 2006. Shrouded Attributes, Consumer Myopia, and Information Suppression in Competitive Markets. Quarterly Journal of Economics 121:505-40.

García, Diego, Francesco Sangiorgi, and Branko Urošević. 2007. Overconfidence and Market Efficiency with Heterogenous Agents. Economic Theory 30:313-36.

Grether, David, Alan Schwartz, and Louis Wilde. 1992. Price, Quality, and Timing of Moves in Markets with Incomplete Information: An Experimental Analysis. Economic Journal 102:754-71.

Harrison, Glenn W. 1994. Expected Utility Theory and the Experimentalists. Empirical Economics 19:223-53.

Jolls, Christine, and Cass R. Sunstein. 2006. Debiasing through Law. Journal of Legal Studies 35:199-241.

Kahneman, Daniel. 2003. Maps of Bounded Rationality: Psychology for Behavioral Economics. American Economic Review 92:1449-76.

Kaplan, Todd R., and Bradley J. Ruffle. 2004. The Self-Serving Bias and Beliefs about Rationality. Economic Inquiry 42:237-46.

Kim, Jeong-Yoo. 2006. Hyperbolic Discounting and the Repeated Self-Control Problem. Journal of Economic Psychology 27:344-59.

Kim, Taehyung, Lucia F. Dunn, and Gene Mumy. 2005. Bank Competition and Consumer Search over Credit Card Interest Rates. Economic Inquiry 43: 344-53.

Kluger, Brian D., and Steve R. Wyatt. 2004. Are Judgment Errors Reflected in 
158 / THE JOURNAL OF LEGAL STUdies / VOLUME 37 (1) / JANUARY 2008

Market Prices and Allocations? Experimental Evidence Based on the Monty Hall Problem. Journal of Finance 59:969-97.

Krueger, Joachim I., and David C. Funder. 2004. Toward a Balanced Social Psychology: Causes, Consequences, and Cures for the Problem-Seeking Approach to Social Behavior and Cognition. Behavioral and Brain Sciences 27: 313-27.

List, John A. 2003. Does Market Experience Eliminate Market Anomalies? Quarterly Journal of Economics 118:41-71.

_ 2006. The Behavioralist Meets the Market: Measuring Social Preferences and Reputation Effects in Actual Transactions. Journal of Political Economy 114:1-37.

Morgan, John, Henrik Orzen, and Martin Sefton. 2006. An Experimental Study of Price Dispersion. Games and Economic Behavior 54:134-58.

Natter, Hedwig M., and Dianne C. Barry. 2005. Effects of Active Information Processing on the Understanding of Risk Information. Journal of Applied Cognitive Psychology 19:123-35.

Puri, Manju, and David T. Robinson. 2007. Optimism and Economic Choice. Journal of Financial Economics 86:71-99.

Rabin, Matthew. 1999. Comment. P. 247 in Behavioral Dimensions of Retirement Economics, edited by Henry Aaron. Washington, D.C.: Brookings Institution Press and Russell Sage Foundation.

Rachlinski, Jeffrey J. 2006. Cognitive Errors, Individual Differences, and Paternalism. University of Chicago Law Review 73:207-29.

Ronnlund Michael, Erik Karlsonn, Erica Laggnas, Lisa Larsson, and Therese Lindstrom. 2005. Risky Decision Making across Three Areas of Choice: Are Younger and Older Adults Differently Subject to Framing Effects? Journal of General Psychology 132:81-92.

Rydval, Ondrej, and Andreas Ortmann. 2004. How Financial Incentives and Cognitive Abilities Affect Task Performance in Laboratory Settings: An Illustration. Economics Letters 85:315-20.

Salop, Stephen, and Joseph Stiglitz. 1977. Bargains and Ripoffs: A Model of Monopolistically Competitive Price Dispersion. Review of Economic Studies 44:493-510.

Schmitt, Pamela M. 2004. On Perceptions of Fairness: The Role of Valuations, Outside Options, and Information in Ultimatum Bargaining Games. Experimental Economics 7:49-73.

Shui, Haiyan, and Lawrence M. Ausubel. 2005. Time Inconsistency in the Credit Card Market. Unpublished manuscript. University of Maryland, Department of Economics, January.

Soman, Dilip, and Amar Cheema. 2004. When Goals Are Counterproductive: The Effects of Violation of a Behavioral Goal on Subsequent Performance. Journal of Consumer Research 31:52-62. 
Sonnemans, Joep. 1998. Strategies of Search. Journal of Economic Behavior and Organization 35:309-32.

Stanovich, Keith E. 1999. Who Is Rational? Studies of Individual Differences in Reasoning. Mahwah, N.J.: Lawrence Erlbaum.

Stanovich, Keith E., and Richard F. West. 2000. Individual Differences in Human Reasoning: Implications for the Rationality Debate. Behavioral and Brain Sciences 23:645-65.

Strack, Fritz, Lioba Werth, and Roland Deutch. 2004. Reflective and Impulsive Determinants of Social Behavior. Personality and Social Psychology Review 8:220-47.

Van den Steen, Eric. 2004. Rational Overoptimism (and Other Biases). American Economic Review 94:1141-51.

Williams, Bernard. 1985. Ethics and the Limits of Philosophy. Cambridge, Mass.: Harvard University Press.

Yang, Sha, Livia Markoczy, and Min Qi. 2007. Unrealistic Optimism in Consumer Credit Card Adoption. Journal of Economic Psychology 28:170-85. 